\title{
Perception Accuracy of Biases in Self and in Others
}

\author{
Hanna Brycz \\ Institute of Psychology, University of Gdansk, Gdansk, Poland
}

There are two kinds of judgments. When you are a judge, and when you are judged.

Antoine de Saint-Exupery, "Fortress"

\begin{abstract}
Three studies showed that the group of observers accurately recognized biases in other people's behaviors while the group of actors was unable to detect the same biases in their own behaviors. The logic and inevitability of biases influenced the estimations of the former. Biases which were positive, beneficial, logical and non-threatening for the self but at the same time uncontrollable were perceived as more accurate by the group of actors. The correlations among the characteristics of biases themselves and between characteristic of biases and the accuracy are suggested as possible explanations. The theoretical background of the studies is embodied as well in tendency-oriented theories (Kahneman \& Tversky, 1973; Fiske \& Taylor, 1984; Kruglansky, 1989) as in new stream of accuracy theories (Haselton \& Buss, 2000; Funder, 1995; Levesque, 1997; Simson, Ickes, \& Grich, 1999).
\end{abstract}

Keywords: accuracy, actor-observer asymmetry, biases

\section{Introduction}

The main aim of the studies is a closer investigation into similarities and differences in the naive bias theories people hold. These similarities and differences are considered in terms of their judgmental process in assessing themselves and others. Another important goal of the presentation is an attempt to establish reasons for the plausible asymmetric pattern in the judgmental processes of own vs. others' biases.

Many psychological studies on attribution perspective have served as reliable sources for predicting these asymmetrical patterns in the judgmental processes. Goals and motives have a great impact on subject vs. observer judgments. The observer perceives and assesses his/her environment solely to understand, check and predict the behaviors of persons known and unknown. The subject is focused on his/her abilities and the social desirability of his/her behaviors, avoiding feeling guilt or shame.

According to Nisbett and Ross (1980), the subject's attributions were a consequence of his/her behaviors, which served, for example, as a foundation for egocentric attribution error. Individual success connected with happiness caused internal attribution to personal abilities and efforts. Individual failure connected with negative emotions, such as, shame, triggered external attribution to environmental factors, even ill fortune. The well-being, self-enhancement and effectiveness of personal behaviors were motives for the course of an actor's life. These main motives, sometimes, gave way to others based on beliefs and values, context and environmental impact. No matter on what ground, the fact is that self-motives work for enhancing self-regulation (Higgins, 1996; Baumeister \& Vohs, 2005). It is interesting that self-enhancement depends upon attaining self-regulation. For example, when you see yourself in a positive light, you are more eager to contact

Hanna Brycz, Ph.D., professor, Institute of Psychology, University of Gdansk. 
another person (Swann, 1990; Dunning, 1993). On the other hand, the same self-enhancement motive might cause lower accuracy in self-perception as opposed to perception of others. Moreover, self-enhancement was not the only factor at play. The self-presentation motive (Bradley, 1978) as well as the self-serving bias (meaning the process of assessing others that favors only those traits valid for self-description) lay at the root of reduced accuracy in self-perception of biases (Lambert \& Wedell, 1991; Markus, Smith, \& Moreland, 1985). Also, the subject's tendency to use a confirmatory attitude in testing hypotheses in everyday life and poor insight into their own emotional life could block accurate perception of biases in one's own behavior.

In other words, the subject's motivation for possessing effective self-regulation and hedonistic motivation might create low accuracy of self-perception. An observer in terms of "an observer of the whole social world", not an observer of people with whom they have a close relationship (Malloy \& Albright, 1990) might use cognitive motivation. This kind of motivation co-appeared with a drive to accurately verify hypotheses about the social world. The line of reasoning supported studies carried out by Semin and Fiedler (1991), which showed a great tendency to speak about oneself and close others in factual, episodic categories and unknown others in general holistic categories. It seems plausible that people create different abstract categories about "whole people" or the "surrounding social world" from categories called "myself" or "my close others".

There is empirical evidence for accurate perception of "the whole people" or "people in general" behaviors. Klayman (1988) showed the accuracy of choosing clues to assess others. Gigerenzer, Hoffrage, and Kleinbolting (1991) provided knowledge of a relatively good level of participant accuracy in judging their own quantity of correct answers about the environment (like a river's length) in a large (but not in a single) number of questions. What is more, people could accurately assess some central traits of unknown individuals on the bases of watching "thin slices of behavior", chosen from the mainstream of behaviors (Levesque \& Kenny, 1993; Ambady, Hallahan, \& Rosenthal, 1995). Moreover, meta-cognitive accuracy for "people in general" is higher than the analogous accuracy for couples (Kenny \& DePaulo, 1993). Chen, Shechter, and Chaiken (1996) showed that asking participants for rational and accurate answers about others was effective and increased accuracy motivation. When people's aim was to be accurate (prompted consciously or automatically) in information seeking and processing, they became intentionally meticulous and deliberate. They postulated a systematic and heuristic type of processing of social information. When people enjoyed a nice evening with friends, they used a heuristic kind of reasoning. When they had any clue to use systematic reasoning, their accuracy increased. The authors verified important phenomena indicating simultaneous usage of both systematic and heuristic reasoning.

It is plausible to expect that the initial concept of "the whole people" revolves around systematic reasoning, instead of searching for episodes in the operating memory of a single person's behaviors. Our knowledge about the behaviors of "people in general" is in fact a kind of common theory of biases. The theory in question is relative only to "the whole people", but not "me". The common theory of biases concerning "people in general" might be accurate, especially when a perceiver is motivated to be rational and is not cognitively loaded.

\section{Measures of Perception of One's Own and Others' Biases}

According to Cronbach (1955), when considering definitions of accuracy, it is important to possess a real standard or criterion for accurate bias perception, a criterion which should allow accurate judgment to be differentiated from inaccurate. In these studies, the ability to recognize a bias in own vs. other's behaviors produced the accurate judgment. In fact, all the biases known in psychological literature were in one way or 
another statistical generalization and as such could have been treated as a criterion of accuracy. However, statistical generalizations also caused difficulties in the search for objective critera (Levesque, 1997), as well as in assessing the level of accuracy for a single participant. Moreover, in that case, accuracy judgment might be measured in the zero-one scale, where zero (0) would indicate incorrect answers and one (1) would indicate accurate recognition of a given bias. The accuracy would be operationalized for: (1) participants and observers, in terms of their compliance in recognizing the given bias in most people's behaviors; or (2) participants - subjects, in terms of their compliance with recognizing the given bias in most personal behaviors.

A list of 129 biases, created on the basis of abundant psychological literature, was adopted for measuring the accuracy of own vs. others' biases and included attribution biases, such as fundamental attribution error (Ross, 1977), perceptual illusions, decision biases, such as post-decided sorrow (Wicklund \& Gollwitzer, 1982), memory biases, such as false alarm, errors in logical thinking and problem-solving, action biases (like self-handicapping) and so forth. Each of the 129 biases was described in terms of behavior, in two sentences, one representing the function of error in real life and the other presenting behavior free of a given bias. Each participant was supplied with a 258 -sentence questionnaire. Two questionnaires, identical in contents but different in forms, were created separately for actors and observers. Actors obtained a questionnaire with sentences formulated around own behaviors (e.g., When I was...), while observers were supplied with a questionnaire based on sentences around other people's behaviors (e.g., When most people were...).

For example, the "gambler's fallacy" was expressed as follows (participants chose only one sentence, which they assumed to be true):

Observer's sentences:

(1) When playing roulette, most people expect that after a series of "red wins" the probability of black winning rise;

(2) When playing roulette, most people expect that after series of "red wins" the probability of black winning is the same.

Actor's sentences:

(1) When playing roulette, I expect that after series of "red wins" the probability of black winning rises;

(2) When playing roulette, I expect that after series of "red wins" the probability of black winning is the same (always 5).

\section{Methodology}

\section{Study 1: First Pilot Inquiry}

The aim of the pilot inquiry was to test how accurate a subject could be in perceiving own vs. others' biases. The main hypothesis assumes an asymmetrical pattern of actor's vs. observer's accuracy, i.e., actor would be less accurate than observer.

Participants and procedure. A group of 205 University of Gdansk undergraduate students anonymously participated in this study (147 females and 58 males). After signing a consent form, students were randomly allocated either to actor (102 participants) or observer (103 participants) conditions. Each participant received a questionnaire (only for actor or observer conditions, separately) with a paragraph activating either actor vs. observer perspective. Each person filled out only one questionnaire. In the instructions, students were always asked to mark only one of two clustered sentences, marking "a" and "b" (out of 258 sentences, paired in 129 indicators of a given bias), which seemed to be true for them. Sentences indicating biases or behaviors free of 
biases were randomly assigned to "a" or "b" for all 129 pairs.

Manipulations. Attribution perspectives were manipulated by a paragraph attached to the top of each questionnaire. All students read about a group of psychologists who were eager to know how a person perceives a given situation. In "observer" conditions, participants learnt that they should rely on their knowledge about "people as a whole", afterwards, they received the questionnaire and read sentences structured "Most people...". In "actor" conditions, students were asked to be focusing on themselves and imagine their probable behaviors in the past or in the future, and afterwards, filled out the questionnaire with sentences structured "I'm...". $\alpha$-Cronbach for actor's questionnaire is 0.92 and $\alpha$-Cronbach for observer's questionnaire is 0.95 , respectively.

Variables. Independent. The attribution perspective: two (actor $\times$ observer) were employed as independent variables.

Dependent. The dependent variable was equal to the measure of accuracy. Each choice between sentences "a" or "b" was accurate when the participant indicated the sentence showing a given bias as true (one mark). General accuracy in (actor $\times$ observer) groups was measured by the frequency of all the choices complying with the existence of all biases.

\section{Results}

Firstly, the level of accuracy was separately analyzed for actor and observer groups.

The accuracy of observers far surpassed expectations. Observers accurately recognized $80 \%$ of biases. $\chi^{2}$ counted separately for each bias was significant $(p<0.001)$ for 108 biases, which meant that the subject explicitly chose the correct sentence that indicating the existence of bias in the everyday life of other people. What's more, within the $80 \%$ of accurately perceived biases, $54 \%$ were accurately recognized by $70 \%$ of participants and $26 \%$ by even $90 \%$ to $100 \%$ of students. Twelve percent were accurately perceived by $50 \%$ of observers and only $8 \%$ of biases were poorly recognized by students assigned to the observer group.

The accuracy of actors was poor, with these subjects accurately recognizing only $18.6 \%$ of biases $(70 \%$ of subjects properly chose the sentence indicating bias). Out of $18.6 \%$ of accurately recognized biases, students were only sure of $3 \%(90 \%-100 \%$ of subjects marked the proper sentence). Correctly recognized biases were as follows: (1) positivity effect in perceiving people; memory bias: (2) false alarm and impact of schemata on better recollection; and (3) reciprocity rule. Participants were blind to almost half of the biases (45.5\%), of which the most inaccurately recognized were halo effect, fundamental attribution error and poor accordance attitudes with behavior. $\chi^{2}$, counted separately for each bias, was also significant $(p<0.001)$.

Secondly, the levels of actor and observer accuracy were compared $\chi_{(d f, N=\operatorname{ILE}(203))}^{2}=548, p<0.001$, with accurate actor's answer $M=18.6 \%$, inaccurate actor's answers $M=81.4 \%$, accurate observer's answers $M=$ $80 \%$ and inaccurate observers' answers $M=20 \%$ (see Figure 1).

One-way ANOVA (analysis of variance): actor vs. observer was computed on accuracy standardized measures and showed the main effect of attribution perspective: $F_{(1,193)}=421.602 ; p<0.001 ; \eta^{2}=0.89$.

Figure 1 shows the participants' great accuracy in recognizing the existence of biases in other people's behaviors (group of observers) and at the same time, the figure reveals that when students judged their own biased behaviors, the accuracy was low (group of actors). It seems plausible to assert that people, as lay bias perceivers, possessed great psychological knowledge about the biased behaviors of others. Participants were, however, unable to see the impact of the same biases on their own behaviors. Some kinds of barriers evidently 
impeded accurate self-perception. When a person was occupied with self and self-related behaviors, the barrier hindered the process of loading the knowledge to the operating memory, which could be called "lay bias theories", the correct psychological knowledge about biases, illusions and errors that everyone possessed with reference to "people in general". It is interesting to see through the barrier, explore its nature and replicate the asymmetrical attribution pattern of bias perception obtained.

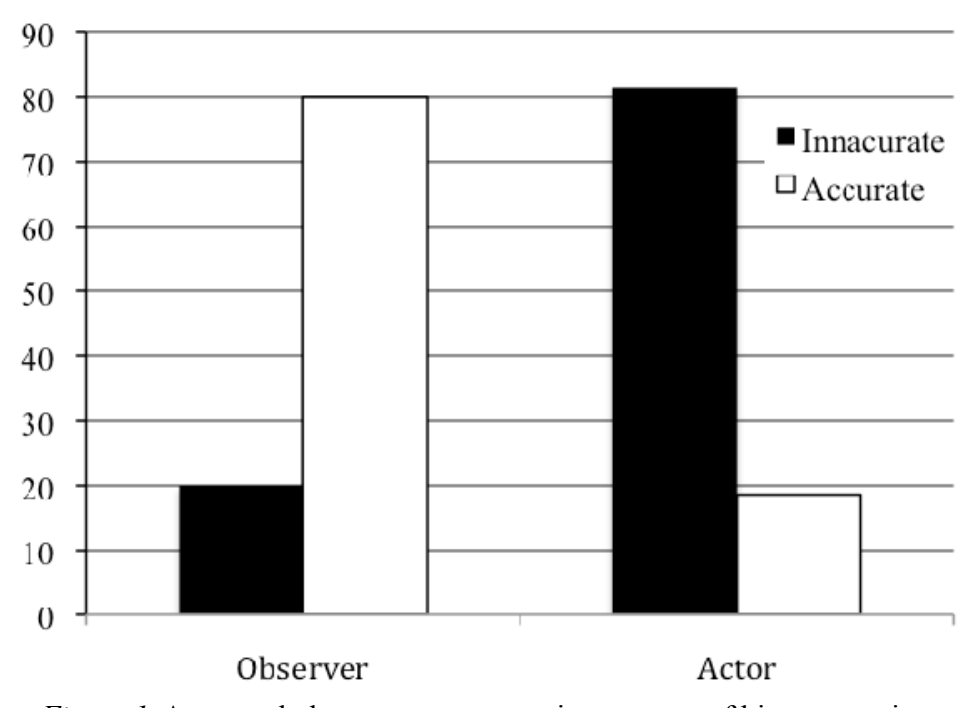

Figure 1. Actor and observer asymmetry in accuracy of bias perception.

\section{Study 2: The Nature of the Barrier: Valence, Logic and Threatening Ego As Features of Biases}

The nature of the barrier that blocked the accuracy of perception of one's own biases might actually lie in the features of the bias itself. Some biases gave credit to the performer, such as pathetic illusion assessing unhappy people, because of failure, for instance, as possessing a better personality than they really had (Deutsch, 1985), and others testified to the less positive side of the performer's personality, such as projection or devil halo effect basing negative judgment of the whole person on one negative trait present, ugliness for instance. Such a kind of social un/desirability of biases might be called "valence". Positive valence of a bias was evidence of social desirability of behavior expressing the given bias. Negative valence of a bias testifies against the social desirability of behavior showing the bias in question.

Motivational factors, such as the self-enhancement motive or avoiding threatening ego, were the basis for predicting poor accuracy of self-perception of negative biases and better accuracy of self-perception of positive biases. It might also be predicted that cognitive motivation would lie behind observers' choices and their high accuracy of both positive and negative biases, although, for this to be true, the valence of biases would have no impact on observers' as opposed to actors' choices.

Another feature of bias is that the logic of bias defines its understandable character. For example, it is easy to understand the spotlight effect or better recollection of schematic information, but difficult to understand overgeneralization biases. The logic of biases constituted a part of cognitive motivation, which should be valuable for observers but also had impact on actor's choices, according to the heuristic — systematic processing of own behavior (Chen et al., 1996).

\section{Hypothesis}

The hypotheses are as follows: 
(1) Valence of biases will have impact only on self-perception of biases and be neutral for analogous perception of others;

(2) Awareness of ego threatening biases will be less accurately perceived by an actor than non-threatening ego biases. This feature of bias will have no impact on observers' levels of accuracy;

(3) Logic biases will be perceived more correctly either by observer or actor.

\section{Method}

Participants. One hundred and twenty-five University of Gdansk undergraduate students participated in the study, 68 female and 57 male.

Procedure and variables. The same procedure was followed as in study 1. Participants were randomly assigned either to the actor or observer attribution perspective.

Besides, three features of biases were of great importance: valence, threatening ego and logic which were selected for future investigation. Different samples of judges (trained psychologists) evaluated each of 129 biases in terms of: its valence $(-5$ negative, +5 positive; $\omega$-Kendall $=0.11, p<0.001)$; its threatening ego character ( -5 not threatening at all, +5 the most threatening; $\omega=0.06, p<0.009)$; its logic ( -5 non-logic at all, +5 most logic; $\omega=0.12, p<0.001)$. What is more, another set of judges assessed whether the given sentence predicting biased behavior out of paired sentences included in questionnaires really expressed the bias in question (from -5 not expressed at all to +5 expressed perfectly). Judges assessed if sentences were in fact good representations of biases $\left(M=4.32, \delta=0.8, \omega_{(2)}=0.61, p<0.001\right)$.

The process of judging also served another purpose, i.e., to count each bias within each characteristic. It appeared that 60 biases were logical and 69 illogical. In addition, the amount of biases with positive valence worked out at 50 items and those with negative 79 . Only 44 biases did not threaten the conscious ego, whereas 85 did.

The other most important aim was to test the hypothesis about the special influence that each characteristic of bias might have on the accuracy of actors' and observers' perceptions of biases. Testing all three hypotheses demanded a count of the beta coefficient in regression analysis, where accuracy was the dependent variable and characters of biases served as independent variables.

\section{Results}

Hypothesis 1 was verified. The valence of biases was significant for the accuracy in the group of actors: $\beta$ $=-0.34, p<0.02$ (for positive biases $M=0.59$ and for negative biases $M=0.44 ; t_{(121)}=-3.09, p<0.001$ ) and insignificant for the accuracy obtained in the group of observers $\beta=-0.06$, n.s. (not significant) (for positive biases $M=0.77$ and for negative biases $M=0.73, t<1$, n.s.).

Hypothesis 2 was also verified. Biases threatening ego were valid only for the accuracy of the group of actors $(\beta=0.31, p<0.02)$ and invalid for the accuracy assessed in the group of observers $(\beta=0.01$, n.s.). Furthermore, this feature of biases was closely correlated with the valence of biases $(r=0.78, p<0.001)$.

Hypothesis 3 was also proved true. The logic of biases was important both for the accuracy of actors $(\beta=$ $0.36, p<0.001)$ and observers $(\beta=0.40, p<0.001)$, which meant that logical biases were perceived more accurately by actors and observers than illogical ones (see Figure 2).

Figure 2 shows the discrepancy between actors' and observers' accuracy (one-way ANOVA showed the main effect of attribution perspective $\left(F_{(1,123)}=57.48, p<0.001, \eta^{2}=0.60, M /\right.$ actor $=0.51$ vs. $M /$ observer $=$ $\left.0.75, t_{(124)}=12.5, p<0.001\right)$. Once more, the asymmetrical attribution pattern in the accuracy of bias 
perception appeared significant. More importantly, as predicted, features of biases were determined as causes for better or poorer accuracy in actors. Positive biases and non-threatening ego were perceived more accurately by actors and then negative and threatening ones. Logical biases appeared to be more accurately perceived both by actors and observers.

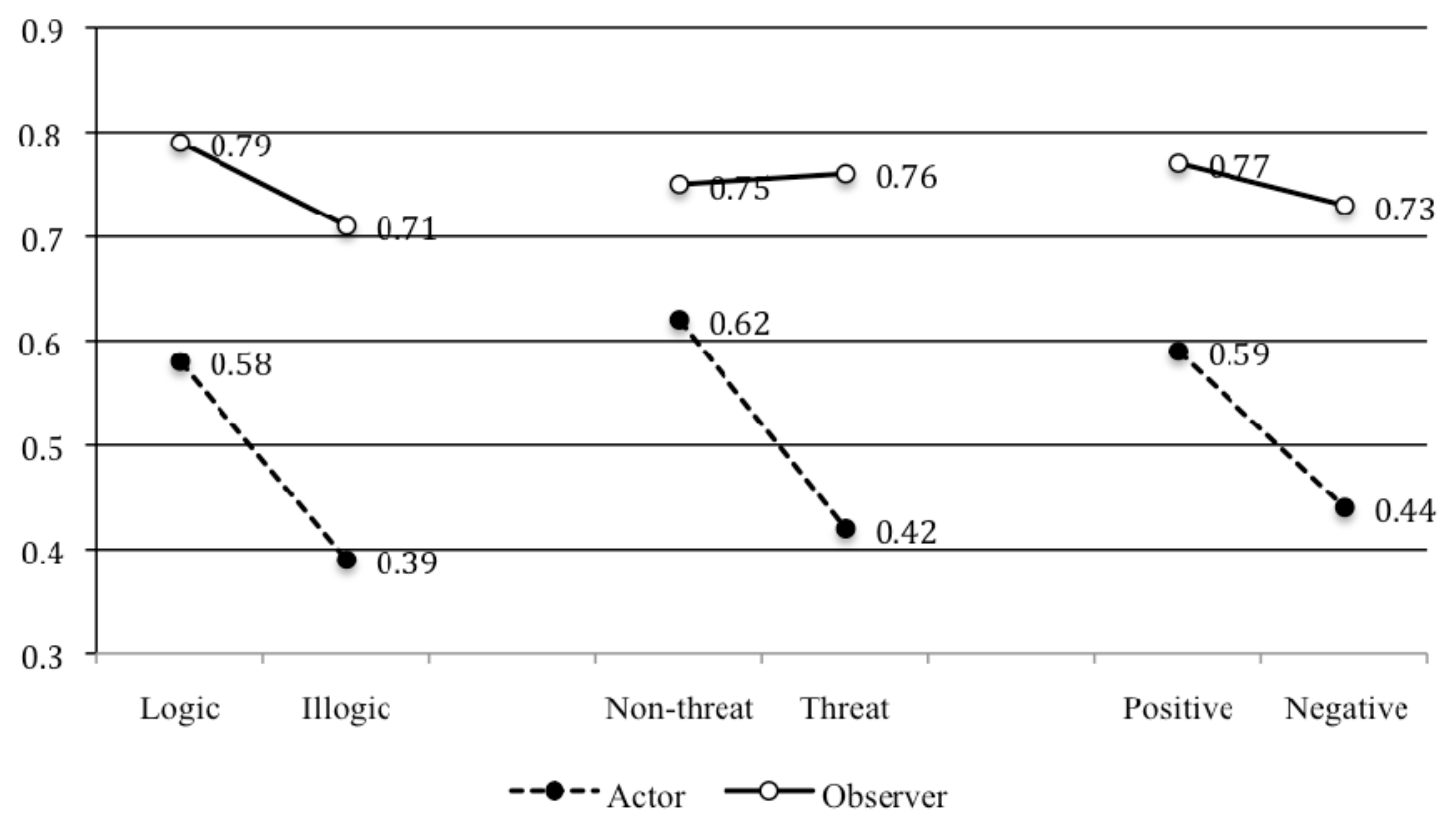

Figure 2. Features of biases and the accuracy of actors' and observers' perception of biases.

Different motives are at work in the perception of one's own and others' biases. When a person assessed his own behavior, he/she displayed helplessness in accurate bias perception. Self-enhancement, self-protection (better perception of positive, non-threatening biases) and cognitive motives (logic biases) were responsible for the phenomenon called the barrier in accurate perception. When a person looked at the biased behaviors of "people in general", he/she was accurate because cognitive motivation served as the only kind of motive.

\section{Study 3: The Other Characteristic of the Barrier: Inevitability and Controllability of Biases}

The inevitability of biases means the universality and necessity that characterizes the appearance of bias amongst most people in the population. Controllability causes some confusion. The word "control" is one of the most overused terms in psychology. We have learnt about self-control, feeling of control, cognitive control, self-regulation, effectiveness, self-determination and so on (Skinner, 1996). Self-determination, for instance, was defined by Deci and Ryan (1985, p. 38) as "human functioning, that includes experience of choice... ability to make a choice... being determinant of own behavior". Control is, sometimes, connected with causality, in which case control is divided into sufficiency and necessity, where sufficiency is the human ability to cause or inhibit an action and necessity the inability of performer's actions to overcome environmental circumstance (Rothbaum, 1981). Self-control is also known as conscious impulse control (Baumeister \& Vohs, 2005).

Controllability in this study meant the human ability to withdraw a bias guiding own behaviors, which withdrawal permitted further bias-free behavior. Comparisons with the laws of physics spring to mind, as it might look like the negation of "Newton's Law of Gravity". In other words, if a ripe apple, falling from the tree, reconsidered its decision, returned and attached itself to the branch again, the apple would have attained controllability. But, apples are incapable of this. Nor do people resemble apples, in that they do possess the ability 
to change their behaviors. They might even switch off biases that impact on their actions. This is controllability.

It seems plausible that the inevitability of biases might improve observers' accuracy. The cognitively motivated observer should be more accurate in recognizing biases in other's behaviors, when biases are more common and more inevitable. On the other hand, controllability might impact on the accuracy of the actor. Hypothetically, there are two ways of predicting. One lies in the chronic human accessibility of self-esteem, self-protective mechanisms and well-being. The latter may cause improvement in the accuracy of perceiving uncontrollable biases which reveal nothing about the performer's social desirability. It is easy to say that "My behavior is out of my control". The other prediction, in contrast to that above, asserts the beneficial impact of controllability on the accuracy of an actor. This is connected with the line of reasoning discussed by Fiske and Taylor (1984) or Brickman (1987), who all maintained the conscious character of controllable actions. This suggested a cognitive motive in processing information about oneself, which might overcome the self-enhancement motive.

\section{Hypothesis}

Hypotheses are as follows:

(1) The accuracy of bias perception will be higher in the group of observers than either in the control group or the group of actors (replication of previously obtained asymmetrical attribution pattern in bias perception);

(2) Inevitability of biases will impact only on the accuracy of observers (inevitable biases will be perceived more accurately than rarer ones) and should not influence the accuracy of actors (actors are interested in themselves and consensus does not matter);

(3) Controllability of biases will be important only for actor's accuracy not for observers'.

\section{Method}

Participants and procedure. Two hundred and seventy-nine Gdansk Medical Academy undergraduate students participated in study 3, participants being randomly assigned to three groups: 88 subjects to the group of actors, 92 to observers and 99 to the control group. The procedure was almost identical to study 1 and study 2. The only difference was the addition of a control group, which filled in a new questionnaire without attribution perspective $(\alpha$-Cronbach $=0.91)$. The questionnaire included the same two-paired sentences for each of the 129 biases, but sentences were expressed in the passive mood, such as "It's said to be...", not "I'm..." (actor), or "Most people..." (observer).

Moreover, each of the 129 biases was assessed by two independent groups of trained psychologists in terms of its controllability and inevitability, respectively (one not at all to seven completely). For inevitability judges' compliance was significant $\omega_{(8)}=0.21 ; \chi_{(d f, N=128 \mathrm{ILE})}^{2}=129.29, p<0.001$ as well as for controllability $\omega=0.19, \chi_{(d f, N=128 \text { ILE })}^{2}=116.79, p<0.001$.

Variables. Independent. Attribution perspective manipulation, described in study 1, served as an independent variable. The control group was not asked to focus either on their own or on others' experiences when filling in the questionnaire.

Other independent variables, which were used for regression analysis, were controllability and inevitability of biases.

Dependent. The level of accuracy always serves as a dependent variable.

\section{Results}

Hypothesis 1 on the asymmetrical attribution pattern of bias perception once more proved significant. 
One-way ANOVA with controlled gender as an independent variable revealed the main effect of perspective: $F_{(2,272)}=112.57, p<0.001, \eta^{2}=0.53$. Gender had no bearing on the result. Once more actors were less accurate $(M=0.50)$ than observers $\left(M=0.72, t_{(179)}=17.56, p<0.001\right)$. Again, as predicted, actors were less accurate even than the control group $\left(M=0.62, t_{(189)}=9.32, p<0.001\right)$, which, in turn, was significantly less accurate than the group of observers, $t_{(189)}=7.36, p<0.001$ (see Figure 3).

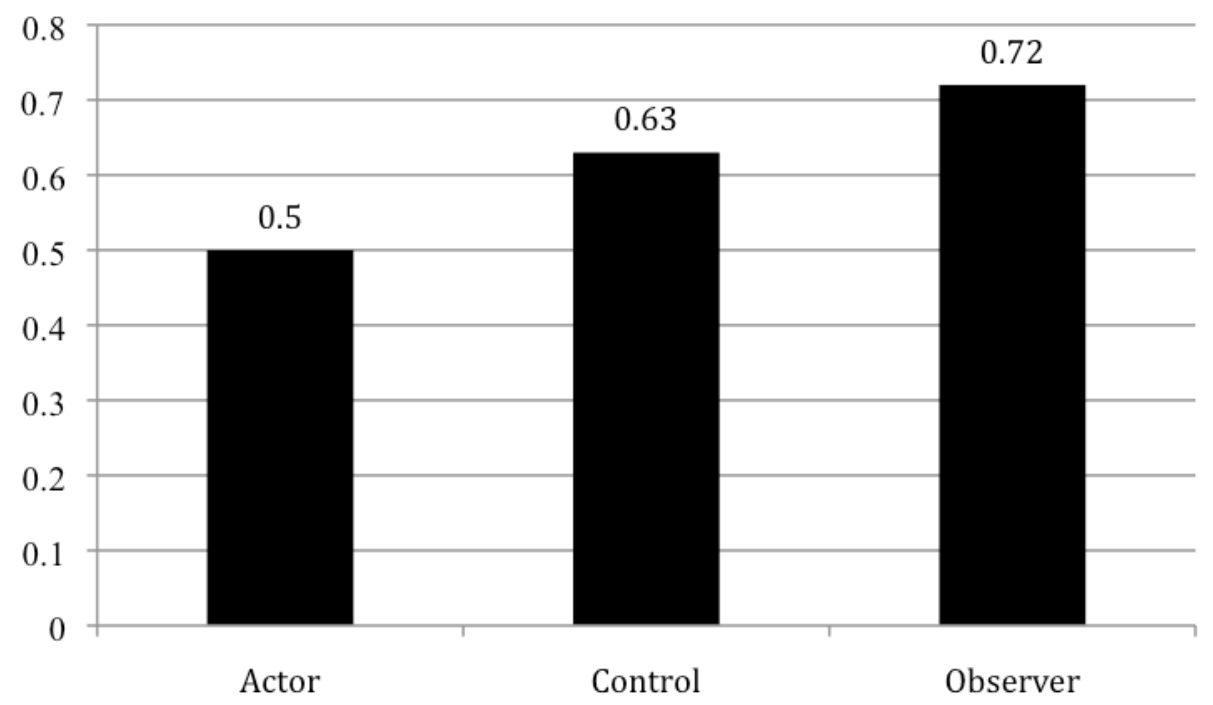

Figure 3. Assymetrical attribution pattern of the accuracy perception in biases.

Figure 3 shows the asymmetrical attribution pattern of the accuracy of bias perception.

Hypothesis 2 concerned the inevitability of biases and its impact on the accuracy level and provided the results predicted. Regression analysis was conducted, where inevitability served as the independent variable and the accuracy of actors and observers the dependent variable. As assumed, inevitability concerned the accuracy of observers $\left(\beta=0.23, t_{(127)}=2.62, p<0.02\right)$ and had no impact on the accuracy of actors' group $(\beta=$ $0.5, t=1$, n.s.). In this group, the accuracy of perception of low inevitable biases $M=0.47$ did not differ from the analogous accuracy concerning high inevitable biases $(M=0.50, t<1$, n.s.). In contrast, the accuracy of observers was better when they perceived high inevitable biases $(M=0.76)$ than in the perception of low inevitable biases $\left(M=0.67, t_{(127)}=2.24, p<0.03\right)$. The control group also did not show any difference between $\operatorname{high}(M=0.64)$ and low inevitable biases $\left(M=0.68, t_{(127)}=1.88\right.$, n.s.) (see Figure 4$)$.

Hypothesis 3 was devoted to the impact of bias controllability on the level of accuracy in perceiving biases in one's own or others' behaviors and also fulfilled suppositions. Regression analysis showed that this feature of biases was important for the group of actors: $\beta=-0.26, t_{(127)}=3.02, p<0.004$ (for low controllability $M=$ 0.50 versus for high $M=0.42, t_{(127)}=2, p=0.05$ ) and irrelevant for the group of observers: $\beta=-0.14, t_{(127)}=$ 1.59 , n.s. (for low controllability $M=0.71$ and for high controllability $M=0.72, t<1$, n.s.) or for control group (for low controllability $M=0.63$, for high $M=0.58, t_{(127)}=1.61$, n.s.). The impact of controllability on the level of accuracy is depicted in Figure 4.

Figure 4 illustrates the fact that inevitable biases were better perceived by observers. This feature of bias was an important factor only for those it concerned directly, i.e., observers, which means that the common appearance of a given bias might be noticed (even unconsciously) only for a person who has made inferences about "the whole people". The same feature was not valid for actors, who tried to evaluate their own behaviors 
without relying on its inevitability among most people. However, controllability was of consequence only to those directed concerned, i.e., actors. Whether or not a person being able to control the given bias in his/her own behaviors did not attract the attention of observers. Controllability was valid only for actors. Moreover, low controllability caused a moderately better level of accuracy in the group of actors than that produced by high controllability. This in turn means that the first assumption about the chronic human accessibility of self-esteem and self-protective mechanisms, in addition to well-being, should be taken into account. Low controllable bias in a person's behaviors revealed nothing about the social desirability or competence of the doer.

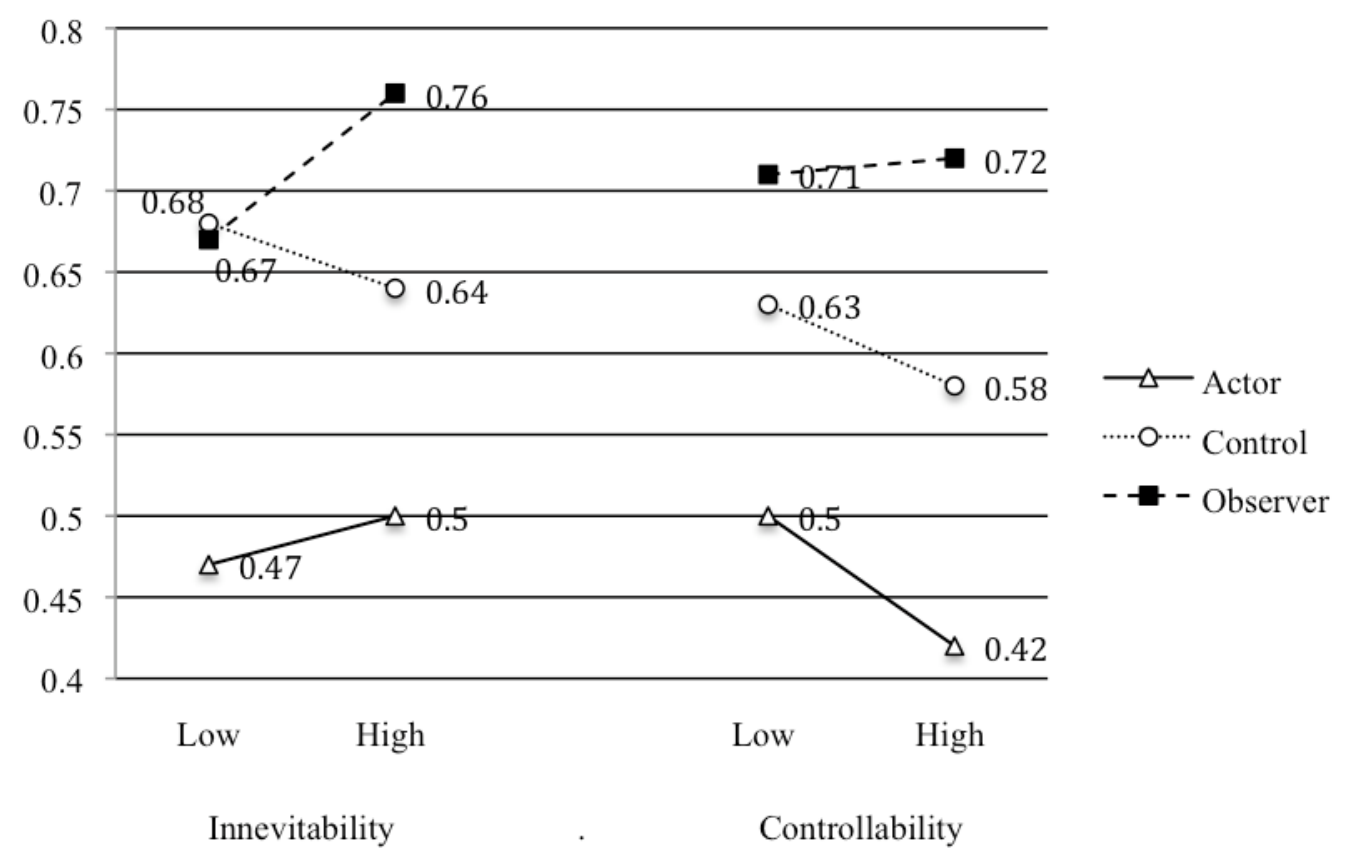

Figure 4. Controllability and inevitability of biases as predictors for the actors' and observers' accuracy.

\section{Discussion}

Three independent studies showed an asymmetrical attribution pattern in the accuracy of bias perception. Participants who assessed their own biases were less accurate than observers or even the control group.

In the pilot study, students, when assigned observer conditions, showed enormous awareness of biases held by "people in general". They possessed great psychological knowledge about biases of "the whole people" illustrated in episodic actions. By contrast, when a person assessed his/her own behaviors which expressed a bias, a kind of invisible barrier prevented them from seeing the truth. They accurately judged only $18.6 \%$ of their own biased behaviors. Why could people not use their astoundingly accurate knowledge about "people in general", included in their naïve bias theory, to assess their own behavior?

That question led to two other studies. Study 2 explored the nature of the invisible barrier in accurate self-perception. Bias features, such as logic, valence and threatening ego, were carefully analyzed to ascertain if they constituted part of the barrier. The results demonstrated that the answer was a definite "yes". Logic, positive and non-threatening ego biases were more properly, in fact moderately (up to 50\%), perceived in own behaviors. Study 2 also replicated the asymmetrical attribution pattern of the accuracy of bias perception.

Study 3 went further in investigating the character of the barrier that hinders accurate recognition of personal biases. Other bias features, such as controllability and inevitability of biases, were at the heart of the 
research. The results showed that inevitability of biases improved the accuracy of observer perception, whereas uncontrollability of biases still increased the accuracy of the group of actors only at a moderate level (50\%). The question why uncontrollability of biases enhanced actor's accuracy is presented in Table 1.

Table 1

Inter-correlations Between the Actor Vs. Observer Accuracy and Features of Biases

\begin{tabular}{|c|c|c|c|c|c|c|}
\hline & 1 & 2 & 3 & 4 & 5 & 6 \\
\hline 1. Logic & - & & & & & \\
\hline 2. Valence & $0.43^{* *}$ & - & & & & \\
\hline 3. Threat to ego & $0.45^{* *}$ & $0.72^{* *}$ & - & & & \\
\hline 4. Controllability & $-0.33^{* *}$ & -0.07 & $-0.22^{* *}$ & - & & \\
\hline 5. Inevitability & $0.19^{*}$ & 0.00 & 0.06 & $-0.34^{* *}$ & - & \\
\hline 6. Actor's accuracy & $0.44^{* *}$ & $0.32^{* *}$ & $0.36^{* *}$ & $-0.27^{* *}$ & $0.19^{*}$ & - \\
\hline 7. Observer's accuracy & $0.25^{* *}$ & -0.15 & -0.04 & -0.15 & $0.20^{* *}$ & $0.45^{* *}$ \\
\hline
\end{tabular}

Notes. $\stackrel{*}{p}<0.05 ;{ }^{* *} p<0.001$ (TRZEBA NAPISAC CZY one-tailed czy - two-tailed).

As it can be seen in Table 1, controllability of biases bore a strongly negative correlation to other bias features like logic inevitability and threatening ego. This outcome was consistent with the hypothesis of the overwhelming impact of the self-enhancement motive on the assessment of self-perception of biases. Moreover, study 3 again replicated the asymmetrical attribution pattern of the accuracy of bias perception.

In all three studies, the leitmotif, which fortunately was always replicated as well as in many other studies conducted by the author and her students, was the asymmetrical attribution pattern of the accuracy of bias perception. The explanation for this result is to be found in the difference between actors' and observers' goals and motives. The observer's goal was solely to remember the concept of "people in general" and their behaviors. They used only cognitive motivation and worked in conditions free from emotional load. They had ideally full resources, and thus, could accurately judge others' biases and base their judgments on cognitive motivation, harnessing logic and inevitability of biases.

Actor's goals were more complex. They tried to bear in mind their own kind of behavioral style, while unconsciously attempting to maintain well-being and self-regard. Mixed cognitive and self-regulatory goals struggled for survival and vied with each other for superiority (Epstein, 1979). Therefore, actors worked in loaded conditions which facilitated automatic self-presentational drive and lowered the accuracy of self-perception.

Moreover, this explanation was supported by the results from investigating bias features. Positive uncontrollable biases, non-threatening to the ego, made it easy to maintain good self-evaluation, although the level of accuracy in perceiving such biases was moderate. The group of actors was completely inaccurate in their perceptions of negative, threatening and controllable biases. Cognitive motivation was represented by better perception of logic biases.

It seems probable to expect that a subject creates and possesses two different kinds of naive bias theories: one to accurately assess "the whole people"-meaning society at large and the inaccurate one, converted to judge "myself" - meaning one's own pool of behaviors. The latter, though incorrect, is in fact adaptive, as it is favorable in terms of courage in social interactions, initiating actions, self-enhancement and hedonism.

The above explanation does not show a black and white picture of human accuracy: good in viewing others and poor in judgments of oneself. In fact, observers are not totally accurate nor actors completely inaccurate. According to Kenny and Albright (1987), social perception is a mixture of accuracy and errors. 
The result concerning controllability merits special attention. It is worth recalling Wannon's (Zuckerman, Knee, Kieffer, Rawsthorne, \& Bruce, 1996) differentiation between realistic and unrealistic control where the former refers to control over controllable situations and the latter concerns events that are genuinely out of one's control. Wannon showed that high realistic and low unrealistic control facilitated pupils' achievement at school, better adapted to school requirements and increasing empathy and competent problem-solving. Zuckerman, Knee, Kieffer, Rawsthorne, and Bruce (1996) showed that people with chronic unrealistic control were prone to repetition, thereby, losing time. Wortman and Brehm (1975) asserted that in really uncontrollable situations, emotion-focused coping functions are more effectively than problem-focused coping.

Returning to our actors' and observers' accuracy, it seems quite unreasonable that actors accurately perceived uncontrollable biases, losing the opportunity to see controllable biases in the correct manner. In other words, actors were inaccurate in assessing biases that were really under realistic control and accurate in judging biases out of their control. The phenomenon at first glance seemed in conflict with reasonable people's adaptation. The explanation for this strange unnatural phenomenon comes from negative correlations among controllability and non-threatening ego, logic, inevitability and actor's accuracy. All in all, a high controllability of biases is linked to threatening ego, lack of logic, infrequency of biases and poor actor's accuracy (see Table 2). By poor accuracy, participants in some way are saying that realistically high controllable biases did not impact on their behavior. On the other hand, they kept their self-regard. Therefore, which is preferable to live in illusions, feel good or lose the biased look at your own behaviors and feel ill at ease? This question demands further researches (Brycz, 2005).

Table 2

Professional Judgments of High vs. Low Controllable Biases in Connection With Other Bias Features, Judged by Trained Psychologists

\begin{tabular}{lllll}
\hline Biases & Controllability & Valence & Threat ego & Logic \\
\hline Low controllable & & & & 1.5 \\
Decision bias & 2.8 & 1 & 1 & 3 \\
Expectance and memory bias & 3.5 & 1.5 & 0 & 3.5 \\
Memory bias-forgetting & 3.1 & 0 & 0 & 3.5 \\
Visibility effect & 3 & 0 & 0 & 3.5 \\
Social facilitation & 3.4 & 2 & 0 & 4.5 \\
Classic conditioning & 2.7 & 0.5 & -0.5 & -4 \\
High controllable & & & & -0.5 \\
Overgeneralization & 5.2 & -3 & -2.5 & -4.5 \\
Complex probability error & 5.3 & -1.5 & 0 & -4.5 \\
Gambler's illusion & 5.2 & -1.5 & -0.5 & -4 \\
Discrepancy: attitude and behavior & 5.5 & -4 & -4 & -3.5 \\
Persuasion bias & 5.8 & -3 & -3 & -2.5 \\
Conformity bias & 5 & -3 & & \\
Controllability scale from one to seven & & & & \\
Rest of scales from -5 to +5 & & & & \\
\hline
\end{tabular}

\section{References}

Ambady, N., Hallahan, M., \& Rosenthal, R. (1995). On judging and being judged accurately in zero-acquaintance situations. Journal of Personality and Social Psychology, 69, 518-529.

Baumeister, R., \& Vohs, K. (2005). Handbook of self-regulation: Research, theory, and applications. New York: The Guilford Press. Bradley, G. W. (1978). Self-serving biases in the attribution process: A reexamination of the fact or fiction question. Journal of Personality and Social Psychology, 36, 56-71. 
Brickman, P. (1987). Commitment, conflict, and caring. Englewood Cliffs: Prentice Hall, Inc..

Brycz, H. (2005). The accuracy of biases perception in one's own vs. others behavior. Kraków: Impulse.

Chen, S., Shechter, D., \& Chaiken, S. (1996). Getting at the truth or getting along: Accuracy-versus impression-motivated heuristic and systematic processing. Journal of Personality and Social Psychology, 71(2), 262-275.

Cronbach, L. (1955). Processes affecting scores on "understanding of others" and assumed similarity. Psychological Bulletin, 52 , 177-193.

de Saint-Exupery, A. (1998). Fortress. Warszawa: PIW.

Deci, E. L., \& Ryan, R. M. (1985). Intrinsic motivation and self-determination in human behavior. New York: Plenum Press.

Deutsch, M. (1985). Distributive justice: A social-psychological perspective. New Haven: Yale University Press.

Dunning, D. (1993). Words to live by: The self and definitions of social concept and categories. In J. Suls (Ed.), Psychological perspectives on the self (pp. 99-126). Hillsdale, N. J.: Erlbaum.

Epstein, S. (1979). The ecological study of emotions in humans. In P. Pliner, K. R. Blankstein, \& I. M. Spigel (Eds.), Advances in the study of communication and affect: Perception of emotion in self and others (Vol. 5, pp. 47-83). New York: Plenum Press.

Fiske, S. T., \& Taylor, S. E. (1984). Social cognition. New York: Random House.

Funder, D. C. (1995). On the accuracy of personality judgment: A realistic approach. Psychology Review, 102, 652-670.

Gigerenzer, G., Hoffrage, U., \& Kleinbolting, H. (1991). Probabilistic mental models: A Brunswikian theory of confidence. Psychological Review, 91, 506-528.

Haselton, M. G., \& Buss, D. M. (2000). Error management theory: A new perspective on biases in cross-sex in mind reading. Journal of Personality and Social Psychology, 78(1), 81-91.

Higgins, E. T. (1996). The "self digest": Self-knowledge serving self-regulatory functions. Journal of Personality and Social Psychology, 71(6), 1062-1083.

Kahneman, D., \& Tversky, A. (1973). On the psychology of prediction. Psychological Review, 80, 273- 251.

Kenny, D., \& Albright, L. (1987). Accuracy in interpersonal perception: A social relations analysis. Psychological Bulletin, 102, 390-402.

Kenny, D., \& DePaulo, M. B. (1993). Do people know how others view them? An empirical and theoretical account. Psychological Bulletin, 114, 145-161.

Klayman, J. (1988). Cue discovery in probabilistic environments: Uncertainty and experimentation. Learning, Memory, and Cognition, 14, 317-330.

Kruglansky, A. (1989). Lay epistemic and human knowledge: Cognitive and motivational bases. Plenum, New York.

Lambert, A. J., \& Wedell, D. H. (1991). The self and the social judgment: Effects of affective reaction and "own position" on judgments of unambiguous and ambiguous information about others. Journal of Personality and Social Psychology, 61, 884-898.

Levesque, M. J. (1997). Meta-accuracy among acquainted individuals: A social relations analysis of interpersonal perception and metaperception. Journal of Personality and Social Psychology, 72(1), 66-74.

Levesque, M. J., \& Kenny, D. A. (1993). Accuracy of behavioral predictions at zero acquaintance: A social relations analysis. Journal of Personality and Social Psychology, 65, 1178-1187.

Malloy, T. E., \& Albright, L. (1990). Interpersonal perception in a social context. Journal of Personality and Social Psychology, $58,419-428$.

Markus, H., Smith, J., \& Moreland, R. L. (1985). Role of the self-concept in the perception of others. Journal of Personality and Social Psychology, 49, 1494-1512.

Nisbett, R., \& Ross, L. (1980). Human Inference: Strategies and shortcomings of social judgment. Englewood Cliffs, New Jersey: Prentice Hall.

Ross, L. (1977). The intuitive psychologist and his shortcomings: Distortions in the attribution processes. In L. Berkowitz (Ed.), Advances in experimental social psychology, 10. Academic Press.

Rothbaum, F. (1981). The effect of sufficiency and necessity on perceptions of control and responsibility. Journal of Personality, 49, 85-100.

Semin, G. R., \& Fiedler, K. (1991). The linguistic cathegory model, its basis, applications and range. In W. Stroebe, \& M. Hewstone (Eds.), European review of social psychology (Vol. 2, pp. 1-30). Chichester: Wiley.

Simson, J., Ickes W., \& Grich, J. (1999). When accuracy hurts: Reactions of anxious-Ambivalent dating partners to a relationship thretening situation. Journal of Personality and Social Psychology, 76, 754-769.

Skinner, E. A. (1996). A guide to construct of control. Journal of Personality and Social Psychology, 71(3), 549-570.

Swann, W. B. J. (1990). To be adored or to be known? The interplay of self-enhancement and self-verification. In E. T. Higgins, \& R. M. Sorrentino (Eds.), Handbook of motivation and cognition: Fundations of social behavior (Vol. 2, pp. 408-448). New York: Guilford Press.

Wicklund, R., \& Gollwitzer, P. (1982). Symbolic self-completion. Hillsdale, N. J.: Erlbaum.

Wortman, C. B., \& Brehm, J. W. (1975). Responses to uncontrollable outcomes: An integration of reactance theory and learned helplessness model. In L. Berkowitz (Ed.), Advances in experimental social psychology (pp. 277-336). San Diego, C. A.: Academic Press.

Zuckerman, M., Knee, C. R., Kieffer, S. C., Rawsthorne, L., \& Bruce L. (1996). Beliefs in realistic and unrealistic control: Assessment and implications. Journal of Personality, 64(2), 436-464. 